\title{
MAPPING ARTIFICIAL TERRACES FROM IMAGE MATCHING POINT CLOUD IN LOESS PLATEAU OF CHINA
}

\author{
J. Na ${ }^{1,2, *}$ X.Yang ${ }^{1}$, X. Fang ${ }^{1,3}$, G. Tang ${ }^{1}$, N. Pfeifer ${ }^{2}$ \\ ${ }^{1}$ School of Geography, Nanjing Normal University, 210023 Nanjing, China - najiaming92@gmail.com; xxinyang@163.com; \\ fangxuan1982@163.com; tangguoan@njnu.edu.cn \\ ${ }^{2}$ Department of Geodesy and Geoinformation, Technische Universität Wien, 1040 Vienna, Austria - \\ norbert.pfeifer@geo.tuwien.ac.at \\ ${ }^{3}$ School of Environment Science, Nanjing Xiaozhuang University, 211171 Nanjing, China
}

KEY WORDS: Loess Plateau of China, UAV, Point Cloud, Artificial Terrace, Image Matching

\begin{abstract}
:
The Loess Plateau of China, as one of the most affected areas in the world, suffers from serious gully erosion due to its fragmented terrains and erosional materials. The farmland is terraced, i.e. artificial terraces are widely constructed in this region from 1960 s to improve the food productivity. While from late 1990s, a project "Grain for Green" start to change those built artificial terraces from the agricultural use into ecologic areas, helping to conserve water. Mapping the artificial terraces, both their distribution and boundaries, is the basis of monitoring their extent and understanding their ecological effects. The drone-based image matching technology provides a possible solution. In this study, an automatic extraction method for artificial terraces was proposed based on the image-matching point cloud. Firstly, an image-matching point cloud was generated using the Pix $4 \mathrm{~d}$ software. Then the vegetation index and height difference were applied on the original point cloud for positive (non-gully) - negative (gully area) terrain segmentation. After that, edge detection on normal vector difference was performed in the non-gully area to define the ridges of artificial terraces. The case study was performed in a small catchment Wucheng in Shanxi province. A comparison between the manual delineation result and the automatic extraction result indicates our method has a total classification accuracy of $85.8 \%$. The proposed method considers comprehensively of topography and landcover. We conclude that it has a an optimistic potential in loess hilly-gully region with similarly complex terrains and diverse vegetation covers.
\end{abstract}

\section{INTRODUCTION}

The Loess Plateau of China is one of the areas in the world that experiences severe soil erosion due to its fragmented terrains, as well as a major agricultural production region in China (Ritsema, 2003). Half a century ago, a project that changes the original terrains in the top of loess hill and hillslopes into the agricultural terraces was started over the whole region. This was one of the main measures for agricultural productivity improvement in this region. The European Common Agricultural Policy also emphasizes the importance of terraces as an integrated system of land and natural resource management (Arnáez et al., 2015). However since 1999, Chinese government began to implement the "Grain for Green" project (Claudio et al., 2015), which change the built artificial terraces from the agricultural use to ecological one. Recovering these terraces into natural land cover like the grassland preforms much better in water and soil conservation than before. Some researchers also reported that terracing enhances water infiltration, reduces soil erosion risks, and improves biodiversity by increasing landscape diversity (Benayas et al, 2007). A series of studies reported on the effects of terraces on soil and water processes, which is an important research field regarding terraces (Strehmel et al, 2015; Shi et al, 2012; Arabi et al, 2008). As from now, most of the formal artificial terraces became the grassland, it is more important to map these artificial terraces, both in its distribution and its boundaries. An automatic method is the basis of monitoring their extent and understanding their current ecological effects at a very huge spatial scale. Previous studies are mainly based on the highresolution imagery, but limitation due to vegetation coverage decreases the accuracy because the artificial terraces are always influenced by the surrounding vegetation in the imagery (Zhao et al., 2017; Zhang et al., 2017). Some methods based on a high-resolution topographic terrain model were proposed (Dai et al., 2017), in which the topographic attributes were considered more likely. However those methods rely on the accurate terrain modelling. Without laser scanning, it will needs lots of effort to produce the data.

With the rapid development of unmanned aerial vehicle (UAV) technology recently, drone-based image-matching photogrammetry shows a strong potential in catchment-scale surveys, which is more flexible and quick than traditional remote sensing. Many researches confirm its robustness and efficiency in monitoring soil erosion (Eltner et al., 2015), terrain modelling, and landslide (Lucieer et al., 2014), in which the generated point cloud by image matching can provide further detailed information. However, since the original generated point cloud still contain the noise and vegetation points, a robust filtering algorithm for Digital Terrain Model (DTM) generation is required. Majority of methods were

\footnotetext{
* Corresponding author
} 
proposed, which are mainly concentrated on the urban area with a relatively gentle flat terrain surface (Turner et al., 2012; Zhang et al., 2017; Zhang et al., 2018). In the mountain area, especially in the gully area, the performances of proposed methods are usually not satisfied, influenced by the huge terrain fluctuation in the gully area. Considering that, this study attempts to propose a proper method for artificial terrace extraction directly based on the image matching point cloud. Furthermore, the accuracy assessment was performed by a case study.

\section{DATA AND METHODOLOGY}

\subsection{Data}

In this study, a small catchment Wucheng $\left(39^{\circ} 16^{\prime} 41.76^{\prime \prime} \mathrm{N}\right.$, $\left.111^{\circ} 34^{\prime} 13.20^{\prime \prime} \mathrm{E}\right)$ of loess-hill landform of approximately $1.5 \mathrm{~km}^{2}$ was selected in the southwest of Pianguan County, Shanxi Province, China. Ranging from 1262.6 to $1519.3 \mathrm{~m}$ in elevation, the selected catchment has a typical loess landform system, consisting of plain area at the top of the hill (positive terrain) and deep gullies (negative terrain). A branch-like gully system was well developed in this catchment, which main gully is about $2 \mathrm{~km}$ in length. On the top of loess hills, most of the terrains were used to be artificial terraced farmland. However, due to the implementation of the Grain for Green project from 1999 , most of those terraces has been changed into grassland or abandoned cropland. Sloping farmland for agricultural use can be still observed rarely in the hillslope.

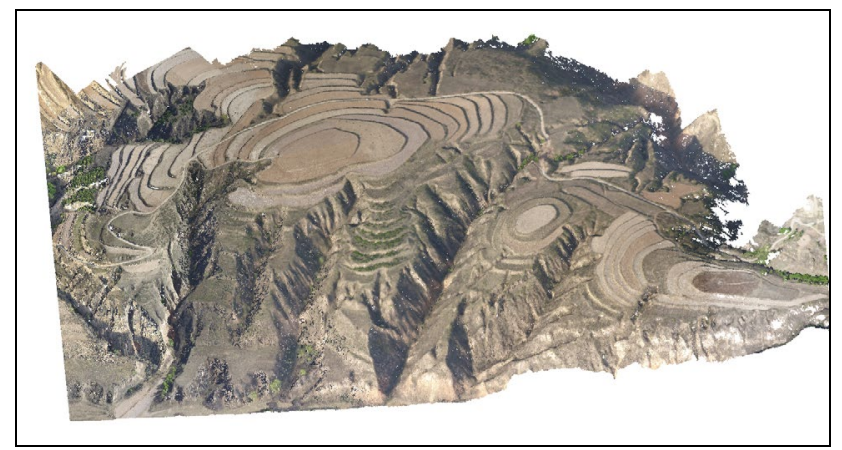

Figure 1. Study Area and Data

Point cloud generated by image matching was used to extract terraces. Original photogrammetric imagery were generated by unmanned aerial vehicles (UAVs) on 26 April 2018. A DJI S1000+ drone system with Sony ILCE-7R camera was applied for the flight. The average flight height is $200 \mathrm{~m}$, which average Ground Sampling Distance (GSD) is about $10 \mathrm{~cm} .367$ images were finally acquired. Data acquisition process was as follows: Firstly, 50 ground control points (GCP) were selected and their geographic coordinates were obtained by the GPS-RTK (Global Positioning System, Real-time Kinematic) method; Secondly, random half of the GCPs were used to update the accuracy of bundle-block adjustment, then the aerial triangulation was performed. At last, the dense point cloud including the vegetation and terrain were generated by image matching algorithm, and another half of GCPs were used for accuracy assessment. The Pix4D software was used for the whole process of data acquisition.

\subsection{Method}

In general, this study uses the morphologic and image feature to identify the artificial terraces. The basic idea is that the artificial terraces have the more plain and flat surface comparing the other natural objects, as well as different landcovers. Fig. 2 shows a height profile of a typical loess gully system. Since the construction work of artificial terraces, forests only in the gully remain. While the terraced area was used to be farmland, it is now grassland. Therefore, this difference can be identified by some vegetation index extracted from the imagery or the point cloud. We use the Green Leaf Index (GLI, Louhaichi et al., 2001), because it only use the visible RGB information. It can be defined as below,

$$
\mathrm{GLI}=(2 \cdot \mathrm{G}-\mathrm{R}-\mathrm{B}) /(2 \cdot \mathrm{G}+\mathrm{R}+\mathrm{B})
$$

where $\quad$ GLI $=$ Green Leaf Index

$\mathrm{R}, \mathrm{G}, \mathrm{B}=$ red, green, and blue values, respectively

On the other hand, the terrain morphologic features can be used to identify each single terrace. Normally, in loess plateau of China, there are three types of artificial terraces, namely level (with a nearly horizontal surface), reversed sloping and sloping (those two with $5^{\circ}$ to $15^{\circ}$ in slope). In the terrace area, since all the ridges are manually made, it will have a very sharp edge from the profiles. Therefore, the terrace has lower roughness than the terrace ridge. In point cloud, the roughness of point can be described as the root mean square (RMS) of Z-values of its neighborhood. The artificial terraces can be easily identified by the roughness, while the ridges can be also detected by the or the $\mathrm{Z}$-axis component of normal vector.

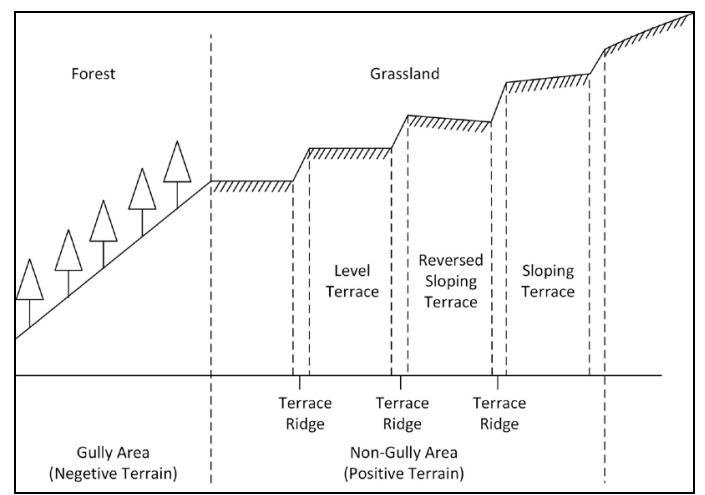

Figure 2. Illustration of the height profiles

In conclusion, the work flow of this study is shown in Fig. 3 as below:

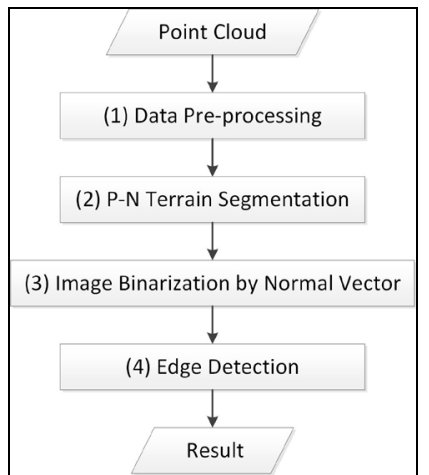

Figure 3. Work flow 
(1) Data Pre-processing. Calculate the normal vector, vegetation index and other attributes of each point in the point cloud.

(2) P-N Terrain Segmentation. Apply the vegetation index and other height difference parameter (roughness and Z-range) to the region-growing segmentation on the point cloud to extract the non-gully area (positive terrain).

(3) Image Binarization by Normal Vector. Resample the points of positive terrain into a grid, and segment the grid using a threshold of Z-axis component of normal vector. A morphological operator was then applied to eliminate the salt and pepper noise.

(4) Edge Detection. Apply canny algorithm for edge detection to get the $2.5 \mathrm{D}$ polylines of terrace's ridges. Then apply LineModeler algorithm (Mandlburger et al., 2016) to get 3D information of the extracted line.

In this study, all the data processing are realized using a modular programming system OPALS developed by Research Group of Photogrammetry in TUWien (Pfeifer et al., 2014).

\subsection{Accuracy assessment}

An proposed indicator, Euclidean Distance Offset Percentage (EDOP), was introduced to compare the results with reference data (Jiang et al., 2015). It assesses the location accuracy by estimating the matching degree between the mapping result and reference data. In detail, it works as follow: Firstly, the reference data is obtained as the ground truth by manual digitalization of a $1 \mathrm{~m}$ orthophoto image in advance. Then the Euclidean distance raster layer (EDRL) with a certain distance (offset $\sigma$ ) of $1 \mathrm{~m}$ is calculated. In this study, $1 \mathrm{~m}$ is selected as the offset distance threshold. This is because according Chinese National Standard (MOHURD of PRC, 2014), the width of terrace ridge should be $1 \mathrm{~m}$. After that, extraction result are intersected with the EDRL. The matched pixels could be considered correct, and the accuracy could be assessed by calculating the ratio of the number of matched pixels out of the total. Typically, the higher the EDOP is, the better the accuracy the method achieves.

\section{RESULTS AND DISCUSSIONS}

\subsection{Results}

\subsubsection{Attribute calculation and segmentation result}

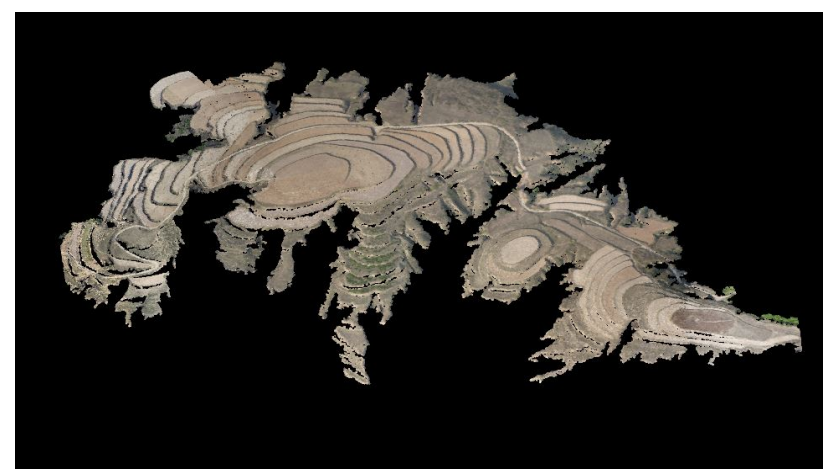

Figure 4. Segmentation result
Figure 4 shows the segmentation result for non-gully area (positive terrain) extraction. A region growing algorithm was used to segment the original point cloud. In study area, the grass just began to grow in April, causing a very low GLI. Therefore, the GLI is considered to make the segmentation, that points with $>0.85$ GLI and its surrounding can be regarded as gully area. The height difference between point and its neighbourhood is also considered to identify the gully area with no vegetation.

\subsubsection{Resampling the point cloud and edge detection result}

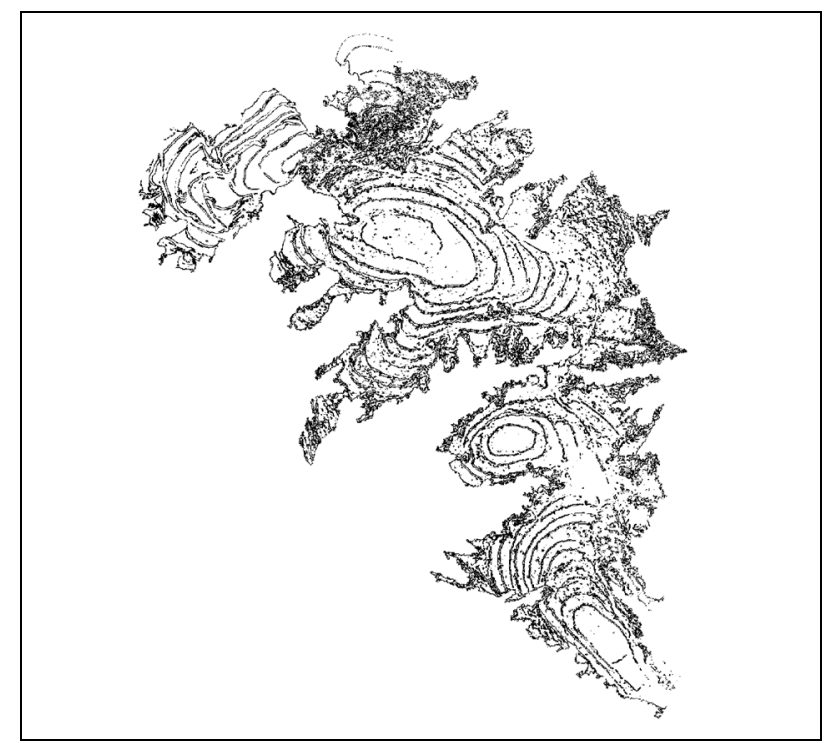

Figure 5a. Normal Vector Segmentation

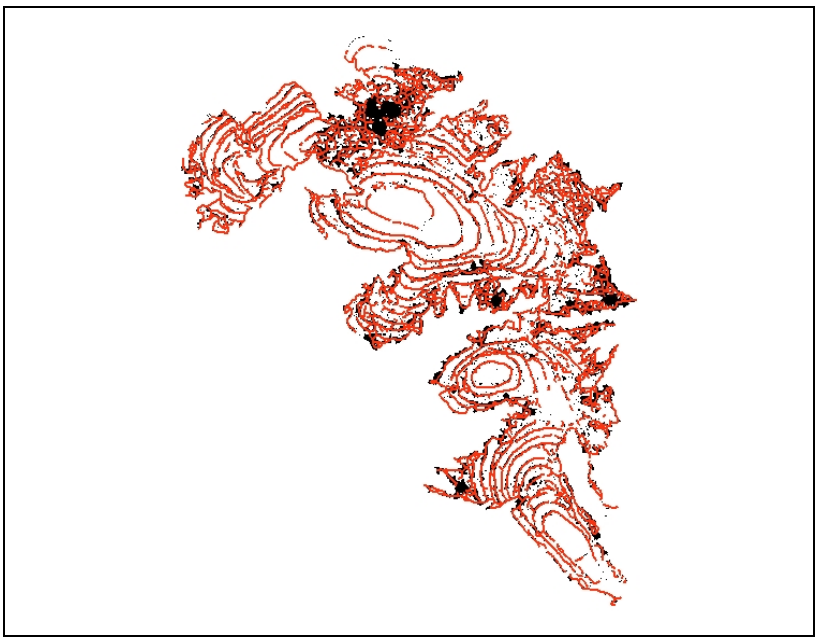

Figure 5b. Edge detection

Figure 5 shows resampling and edge detection. After the nongully area extraction, the remaining point cloud was resampled into $0.5 \mathrm{~m}$ grid. Change of normal vector was then segmented using a threshold of 0.85 (Figure 5a). Dark pixels indicate likely the ridges of artificial terraces. A combination of morphologic dilation and erosion was then operated for 3 times to eliminate the salt and pepper noises. Finally, the canny algorithm was performed to extract the polylines (Figure $5 b$ ).

\subsubsection{Final result and accuracy assessment}

Shown in Figure 6, visualization of overlapping the reference and extraction result shows the success of our method, and 
quantitative analysis was done by using the EDOP as mentioned. The EDOPs of original result in 3 random-selected areas were calculated as follow, $85.2 \%, 87.1 \%$ and $88.1 \%$. The average EDOP $86.8 \%$ can be seen as an estimate overall accuracy because it is very time-consuming for the manual interpretation for the whole area. It is noticed that because some noises still exist during the edge detection process, the result has some small mistakes, which can be further removed manually.

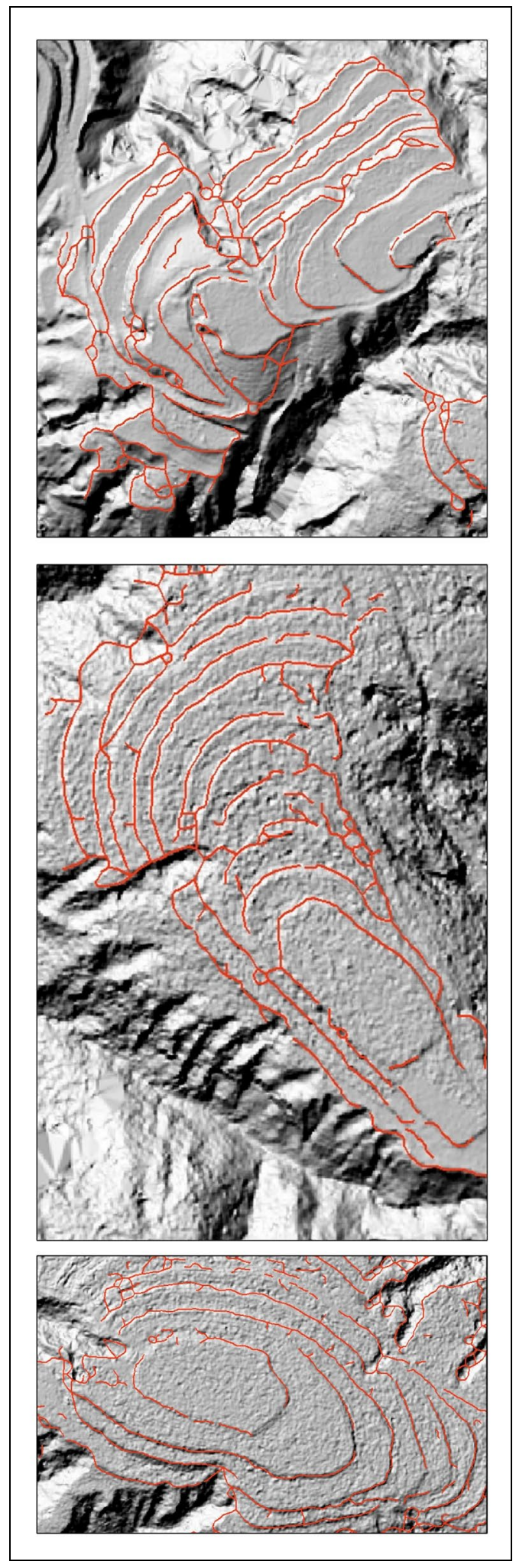

Figure 6. Final result
It should be noticed that in the result, there are some small fragments. This is because the morphological operation for normal vector segmentation result cannot eliminate all the noises, as well as the local change of normal vector can be also detected. And also, the result may sometimes be discontinuous because of the ridges are identified by point instead of a whole line.

\subsection{Discussions}

As mentioned above, the proper threshold of normal vector for segmentation is the key of the proposed method. In fact, artificial terraces in loess plateau of China vary in landscape. Therefore there should be some slight differences when applying this method to the other area. But based on the field survey and construction standard, the vertical angle of the ridge should be not smaller than 60 degree. This indicates that the threshold of Z-axis component of normal vector should be no larger than 0.86. Another test in another catchment in Changwu Country, Shaanxi Province confirms this assumption (shown in Figure 7 as below). However, for other areas outside this region, it is believed that this threshold can be optimized by field work to measure this angle.

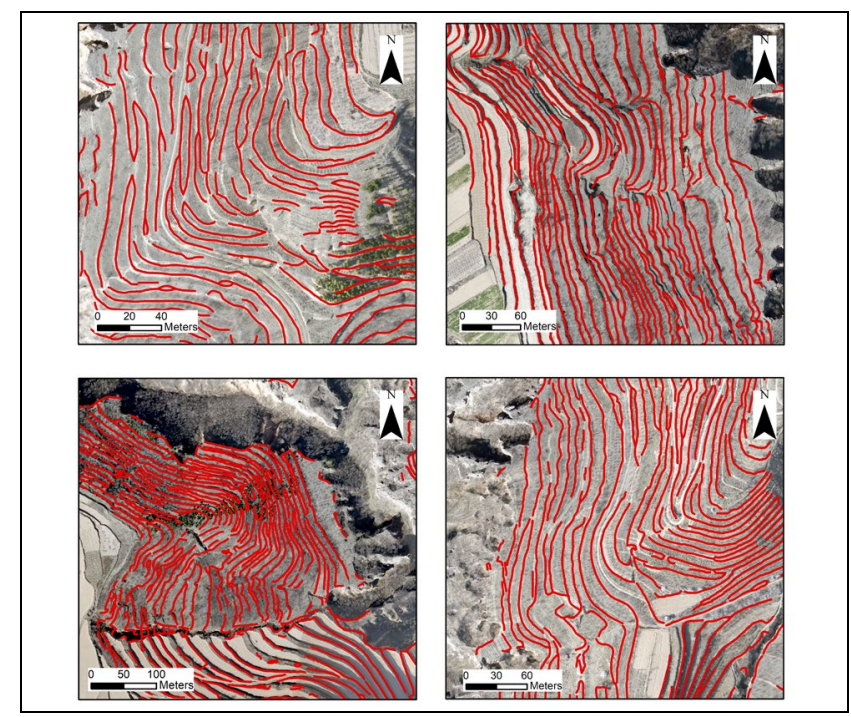

Figure 7. Extraction result in Changwu

\section{CONCLUSION AND FUTURE WORK}

Image-based artificial terrace extractions are strongly influenced by vegetation. DTM-based methods can perform much better, while the data generation is very time-consuming specially if there is a lack of laser scanning data. Proposed vegetation filtering algorithms for imagery matched point cloud usually failed in mountain area because of the huge terrain fluctuation. Therefore, in this study we propose an extraction method for artificial terraces directly based on the image matching point cloud. A case study was carried out, in which the overall accuracy of $86.8 \%$, indicated that proposed method meets the needs of terrace monitoring in catchment scale in the Loess Plateau. An experiment in another loess gully area shows that this method is easy to implement in other area.

The image quality (e.g. camera and flight height) will influence the resolution of the point cloud which is important for extraction. The timing (e.g. season and time) of flight will also 
influence the image in shadow or vegetation. However, the process of the edge detection may cause many small mistakes, like the local change of normal vector can be also detected, or the result may be discontinuous. Future work will optimize the edge detection process to achieve a better result.

\section{ACKNOWLEDGEMENTS}

Authors thank the research group of photogrammetry in Technishe Universität Wien, Austria, who developed the OPALS software and offered a free scientific user license. We are grateful for the financial support from the National Natural Science Foundation of China (Grant No. 41671389, 41771415), the National Natural Science Foundation of Jiangsu Province of China (Grant No. BK2016118) and the Project Funded by the Priority Academic Program Development of Jiangsu Higher Education Institutions (No.164320H116).

\section{REFERENCES}

Arabi, M., Frankenberger, J.A., Engel, B.A., Arnold, J.G., 2008. Representation of agricultural conservation practices with SWAT. Hydrol. Process., 22, 3042-3055.

Arnáez, J., Lana-Renault, N., Lasanta, T., Ruiz-Flañoa, P., Castroviejoa, J., 2015. Effects of farming terraces on hydrological and geomorphological processes. Catena, 128, 122-134.

Benayas, J. R., Martins, A., Nicolau, J. M., Schulz, J. J., 2007. Abandonment of agricultural land: an overview of drivers and consequences. CAB reviews: Perspectives in agriculture, veterinary science, nutrition and natural resources, 2(57), 1-14.

Dai W., Na J., Yang X., et al. 2017. An automatic retrieval method for artificial terrace Based on illumination model of DEM shading. Journal of Geo-information Science, 19(6):754762.

Delang, Claudio O., Yuan, Z., 2015. China's Grain for Green Program, Springer,

Eltner, A., Baumgart, P., Maas, H.G., Faust, D., 2015. Multitemporal UAV data for automatic measurement of rill and inter-rill erosion on loess soil. Earth Surf. Process. Lanf., $40,741-755$.

Jiang, S., Tang, G., Liu, K., 2015. A new extraction method of loess shoulder-line based on Marr-Hildreth operator and terrain mask. PLOS ONE, 10(4), e0123804.

Louhaichi, M., Borman, M.M., Johnson, D.E., 2001. Spatially located platform and aerial photography for documentation of grazing impacts on wheat. Geocarto International, 16, 65-70.

Lucieer, A., de Jong, S., Turner, D., 2014. Mapping landslide displacements using Structure from Motion (SfM) and

image correlation of multi-temporal UAV photography. Prog. Phys. Geogr., 38, 97-116.

Mandlburger, G., Otepka, J., Briese, C., Mücke, W., \& Brockmann, H., 2016. Automatische Ableitung von Strukturlinien aus 3D-Punktwolken. Dreiländertagung der $D G P F$, der $O V G$ und der SGPF in Bern, SchweizPublikationen der DGPF, 25, 131-142.
MOHURD of PRC (Ministry of Housing and Urban-Rural Development of People's Republic of China) and AQSIQ of PRC (General Administration of Quality Supervision, Inspection and Quarantine of the People's Republic of China), 2014. Code for design of soil and water conservation engineering (GB 51018-2014).

Ritsema, C.J., 2003. Introduction: Soil erosion and participatory land use planning on the Loess Plateau in China. Catena, 54, 15 .

Strehmel, A., Jewett, A., Schuldt, R., Schmalz, B., Fohrer, N., 2015. Field data-based implementation of land management and terraces on the catchment scale for an eco-hydrological modelling approach in the Three Gorges Region, China. Agric. Water Manag., 175, 43-60.

Shi, Z.H., Ai, L., Fang, N.F., Zhu, H.D., 2012. Modeling the impacts of integrated small watershed management on soil erosion and sediment delivery: A case study in the Three Gorges Area, China. J. Hydrol., 438, 156-167.

Turner, D., Lucieer, A., \& Watson, C., 2012. An automated technique for generating georectified mosaics from ultra-high resolution unmanned aerial vehicle (UAV) imagery, based on structure from motion (SfM) point clouds. Remote sensing, 4(5), $1392-1410$.

Pfeifer, N., Mandlburger, G., Otepka, J., Karel, W., 2014. OPALS - A framework for Airborne Laser Scanning data analysis. Computers, Environment and Urban Systems, 45, 125 $-136$.

Zhang, J., Lin, X., 2017. Advances in fusion of optical imagery and LiDAR point cloud applied to photogrammetry and remote sensing. International Journal of Image and Data Fusion, 8(1), $1-31$.

Zhang, Y., Shi, M., Zhao, X., Wang, X., Luo, Z., 2017. Methods for automatic identification and extraction of terraces from high spatial resolution satellite data (China-GF-1). International Soil and Water Conservation Research, 5(1), 1725 .

Zhang, Z., Gerke, M., Vosselman, G., \& Yang, M. Y., 2018. Filtering photogrammetric point clouds using standard lidar filters towards $\mathrm{dtm}$ generation. ISPRS Annals of Photogrammetry, Remote Sensing \& Spatial Information Sciences, 4(2),319-326.

Zhao, H., Fang, X., Ding, H., Josef, S., Xiong, L., Na, J., \& Tang, G., 2017. Extraction of terraces on the Loess Plateau from high-resolution DEMs and imagery utilizing object-based image analysis. ISPRS International Journal of GeoInformation, 6(6), 157.

Revised April 2019 